\title{
Communications
}

\section{Circularly Polarized U-Slot Antenna}

Kin-Fai Tong and Ting-Pong Wong

\begin{abstract}
Circularly polarized single-layer U-slot microstrip patch antenna has been proposed. The suggested asymmetrical $U$-slot can generate the two orthogonal modes for circular polarization without chamfering any corner of the probe-fed square patch microstrip antenna. A parametric study has been carried out to investigate the effects caused by different arm lengths of the U-slot. The thickness of the foam substrate is about $8.5 \%$ of the wavelength at the operating frequency. The $3 \mathrm{~dB}$ axial ratio bandwidth of the antenna is $4 \%$. Both experimental and theoretical results of the antenna have been presented and discussed.
\end{abstract}

Index Terms-Circular polarization, printed antennas, U-slot.

\section{INTRODUCTION}

Broadband single-layer U-shaped slot microstrip patch antennas were first proposed by Lee, et al. [1], [2]. Impedance bandwidth $\left(\left|\mathrm{S}_{11}\right|<-10 \mathrm{~dB}\right)$ of more than $30 \%$ can be easily achieved by introducing a U-shaped slot into a conventional probe-fed microstrip patch antenna. A lot of work has been reported on modelling the antennas [3], improving the impedance bandwidth and suppressing the cross-polarizations of the antennas [4]-[6] since then.

Circularly polarized $(\mathrm{CP})$ antennas can reduce the loss caused by the misalignment between the signal and the receiving antenna. It has been widely applied to satellite communication systems, such as MSAT and GPS. The two nearly degenerated resonant modes for circular polarization in single-fed microstrip antennas are usually achieved by cutting diagonal slits or attaching stubs to the corners of a square patch. However, the $3 \mathrm{~dB}$ axial ratio bandwidths of these approaches are narrow (1\% or less) [7], [8].

In this article, the broadband technique used in single-layer probe-fed U-slot patch antennas has been extended to circularly polarized radiation. The proposed asymmetrical U-slot structure can generate the two orthogonal modes for $\mathrm{CP}$ radiation; therefore, no extra stabs or chamfering at the corners of the square patches is necessary. Moreover, the design has a relatively wider axial ratio bandwidth when compare to other single-fed CP microstrip antennas.

The design was first started from deciding the dimensions of a linearly polarized U-slot square patch antenna at the desired frequency, i.e., $2.3 \mathrm{GHz}$ in this article. Detailed design guidelines of $\mathrm{U}$-slot square patch microstrip antennas operating at different frequency bands can be found in [3]. Then one of the arms of the U-slot was shorten to achieve the desired circular polarization. A parameter study of the relation between the arm lengths of the U-slot and the axial ratio of the CP antenna has been carried out. Finite ground plane structure has been considered in the simulation. Impedance bandwidth, gain, axial ratio and radiation patterns of the antennas have been measured and were compared to the simulations.

Manuscript received November 30, 2006; revised March 23, 2007.

K.-F. Tong is with the Department of Electronic and Electrical Engineering, University College London, London WC1E 7JE, U.K. (e-mail: k.tong@ ee.ucl.ac.uk)

T.-P. Wong is with the Department of Electronic Engineering, City University of Hong Kong, Kowloon, Hong Kong.

Digital Object Identifier 10.1109/TAP.2007.901930

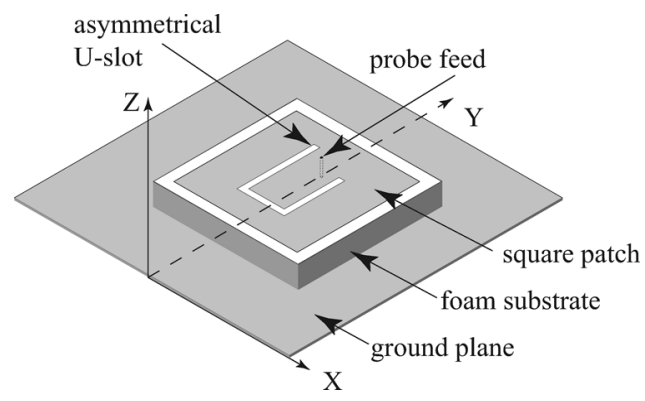

Fig. 1. Geometry of the circularly polarized U-slot patch antenna.

TABLE I

DIMENSIONS OF THE FABRICATED ANTENNA (IN MILLIMETERS)

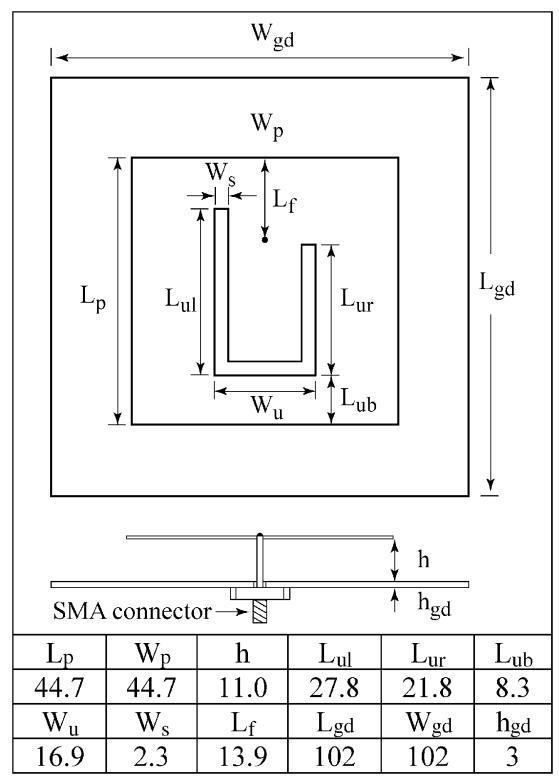

\section{ANTENNA GEOMETRY}

The geometry of a circularly polarized U-slot antenna is shown in Fig. 1. The single-layer antenna is basically symmetrical along the $y z$-plane. The only asymmetrical structure is the U-slot, i.e., the arms are of different lengths. The U-slot is located on the microstrip square patch which sits on the top of a piece of $11 \mathrm{~mm}$ thick foam substrate $\left(\varepsilon_{\mathrm{r}} \cong 1\right)$. The thickness of the foam substrate is around $8.5 \%$ of the wavelength at the centre operating frequency $(\lambda o)$. The feeding probe connected to the U-slot patch passes through the ground plane and the foam substrate from the back of the antenna. The probe is offset from the top edge of the patch by $\mathrm{L}_{\mathrm{f}}$.

By adjusting the length of an arm of the U-slot (either $\mathrm{L}_{\mathrm{ul}}$ or $\mathrm{L}_{\mathrm{ur}}$ ) to the optimum position in $y$-direction, good circularly polarized radiation can be achieved. In Fig. 1, the left arm of the U-slot $\left(\mathrm{L}_{\mathrm{ul}}\right)$ is longer than the right arm, i.e., $\mathrm{L}_{\mathrm{ul}}>\mathrm{L}_{\mathrm{ur}}$, the antenna is left-hand circularly polarized. Right-hand circular polarization can be obtained if $\mathrm{L}_{\mathrm{ul}}$ is shorter than $\mathrm{L}_{\mathrm{ur}}$. The other parameters of the antenna can be found in Table I. 


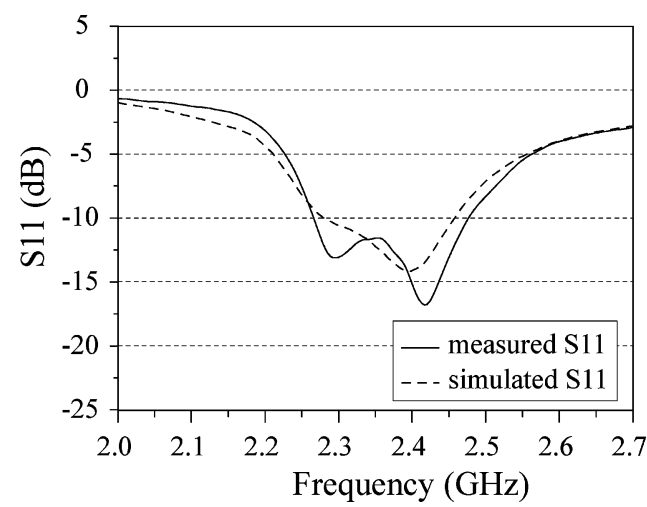

Fig. 2. Return losses of the proposed CP U-slot antenna.

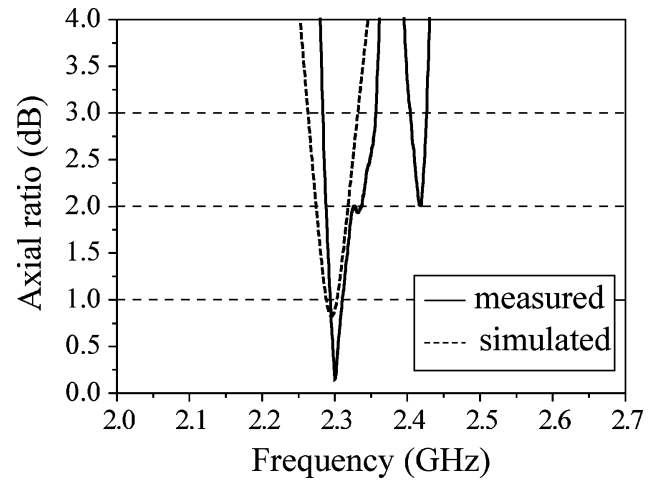

Fig. 3. Axial ratio of the proposed CP U-slot antenna.

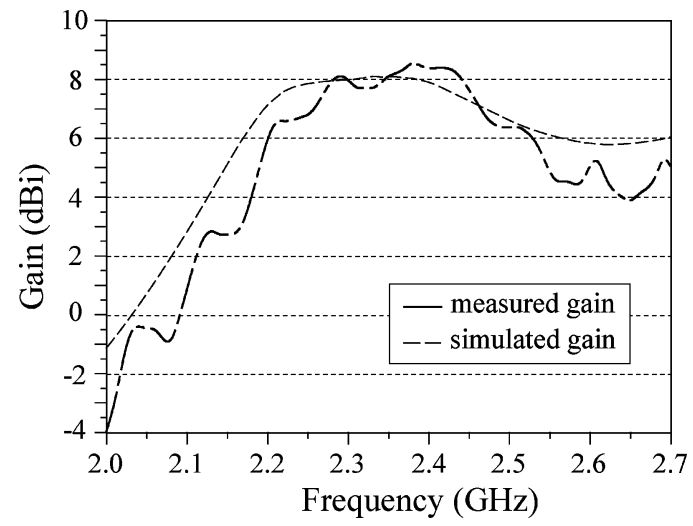

Fig. 4. Gains of the proposed CP U-slot antenna.

\section{RESUlTS AND DISCUSSION}

The CP U-slot antenna of parameters listed in Table I has been fabricated and measured to compare the simulated results. Zeland IE3D has been used in the theoretical calculations. The return loss shown in Fig. 2 was measured by a HP8510C vector network analyzer. The proposed antenna operates at $2.3 \mathrm{GHz}$. Reasonable good agreement between the simulation and measurement can be observed, although the measured return loss shifts slightly to higher frequency. The deviation is mainly caused by the fabrication inaccuracy, especially when stacking layers of foam substrate to achieve the desired thickness $h$. The measured impedance bandwidth $\left(\left|\mathrm{S}_{11}\right|<-10 \mathrm{~dB}\right)$ of the antenna is about $9 \%$, from 2.27 to $2.48 \mathrm{GHz}$. It should be worth mentioning that this work is focus on optimizing the $3 \mathrm{~dB}$ axial ratio bandwidth of the single-fed CP U-slot antenna, rather than widening the impedance bandwidth.

The axial ratio, radiation patterns and gain of the antenna have been measured inside an antenna chamber with a pair of conical log spiral

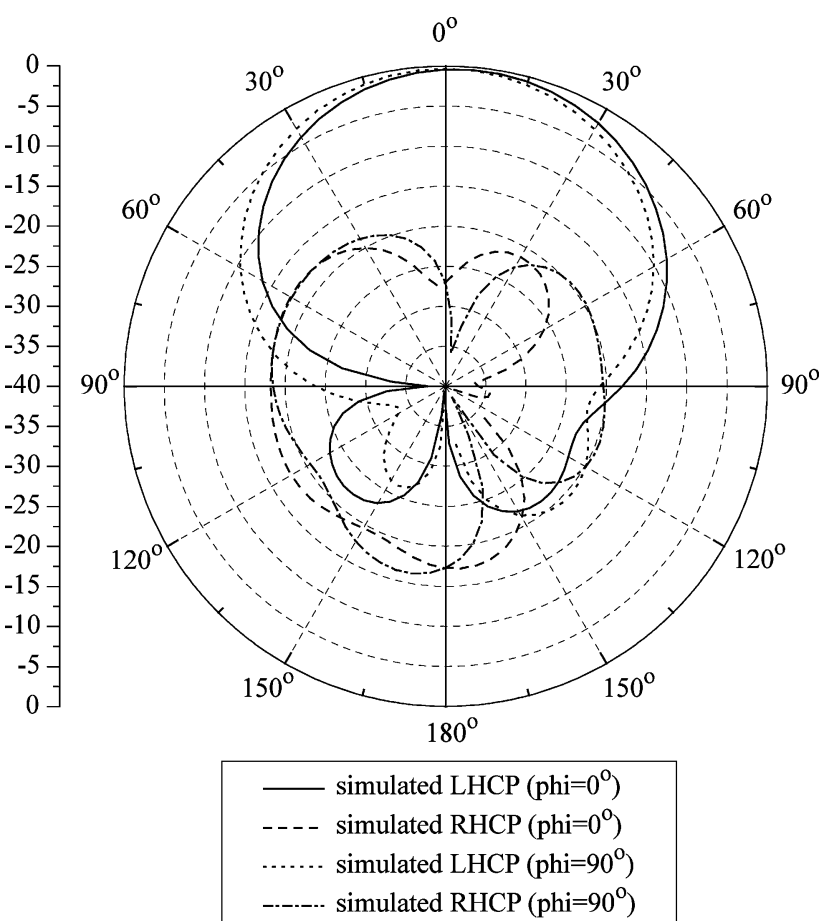

(a)

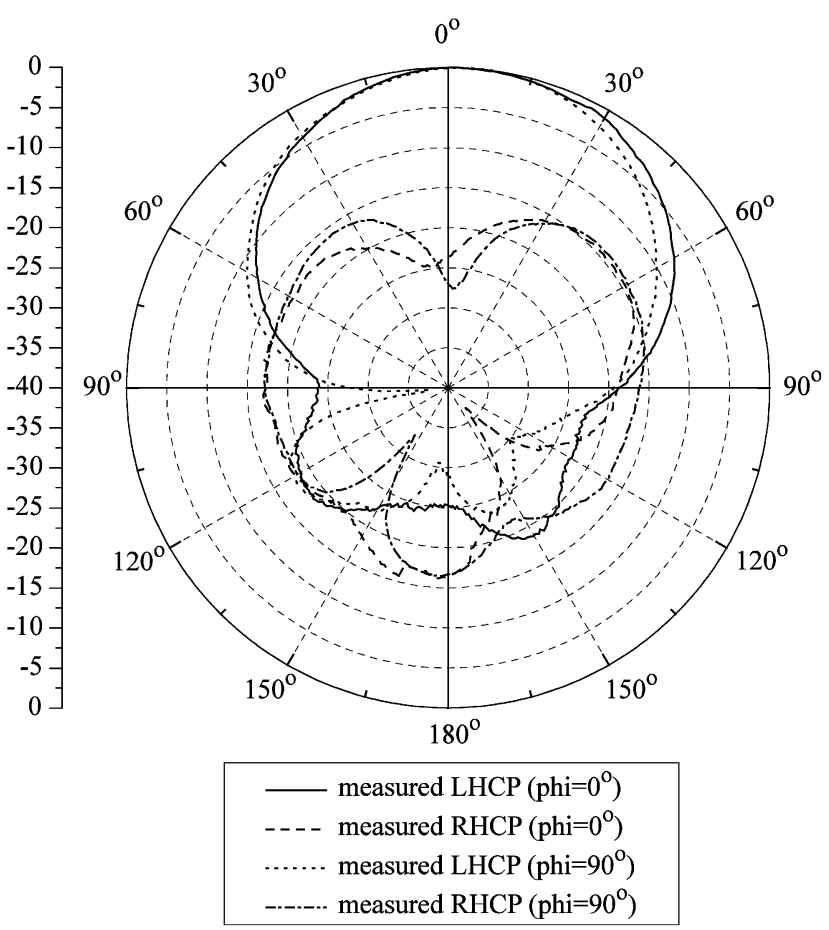

(b)

Fig. 5. (a) Simulated and (b) measured radiation patterns of the antenna at $2.3 \mathrm{GHz}$.

antennas. Both simulated and measured axial ratios are shown in Fig. 3. The measured $3 \mathrm{~dB}$ axial ratio bandwidth is about $4 \%$, from 2.27 to $2.36 \mathrm{GHz}$. Again the measured result shifts slightly to higher frequency which agrees with the trend observed in impedance bandwidth.

The average measured gain across the pass band is about $8 \mathrm{dBi}$, as shown in Fig. 4. The simulated and measured radiation patterns at 2.3 $\mathrm{GHz}$ are shown in Fig. 5(a) and (b), respectively. Boresight radiation patterns can be observed. The $3 \mathrm{~dB}$ beamwidths of the antenna in both 


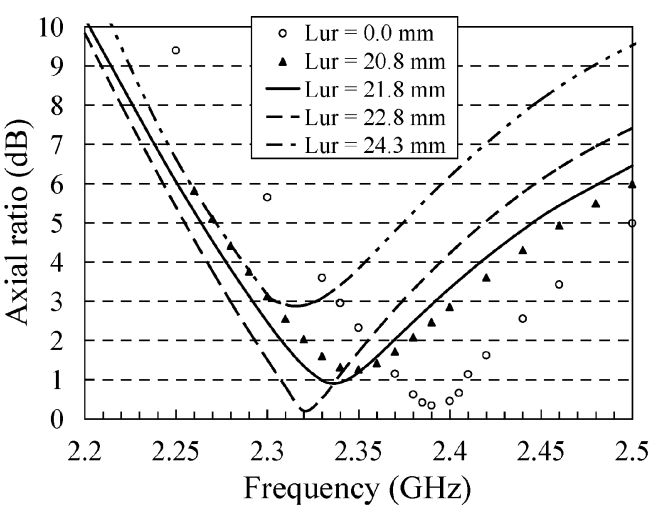

(a)

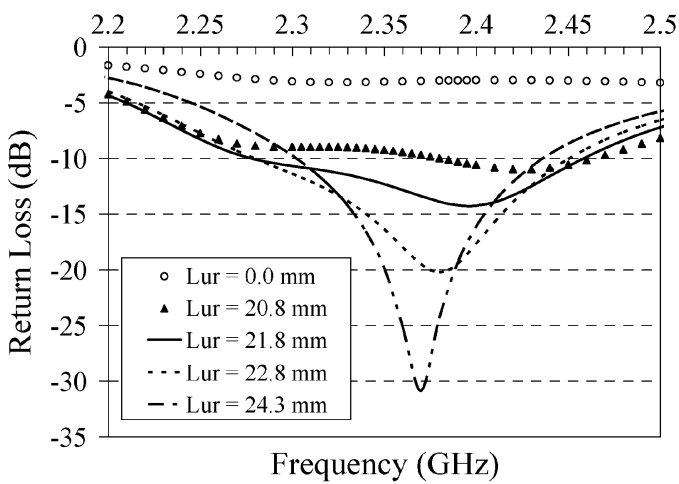

(b)

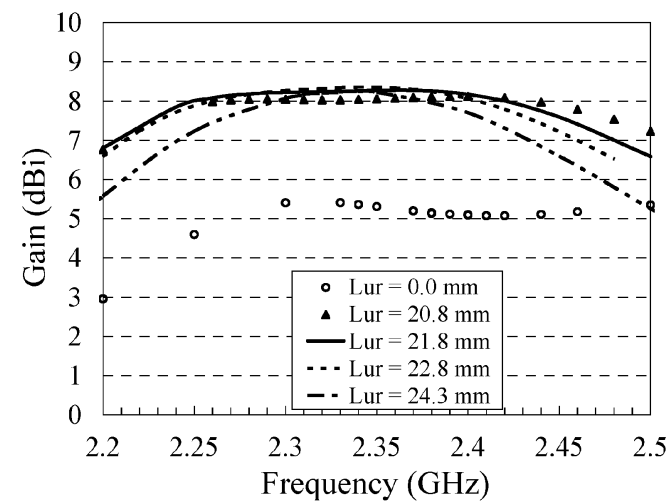

(c)

Fig. 6. (a) Axial ratio, (b) return loss, and (c) gain of the antenna against arm length of the U-slot $\left(\mathrm{L}_{\mathrm{ur}}\right)$.

$x z-\left(\mathrm{phi}=0^{\circ}\right)$ and $y z$-plane $\left(\mathrm{phi}=90^{\circ}\right)$ are about $58^{\circ}$. There is about $15 \mathrm{~dB}$ difference between the measured LHCP and RHCP radiations. The radiation patterns and gain are stable across the pass band.

\section{PARAmetric Study OF THE ARM LeNGTH LUR}

As a systematic study of the effects caused by varying different parameters of the symmetrical U-slot square patch antenna can be found in [3], the authors will only present their investigation the effects caused by the asymmetrical U-slot.

The axial ratios, return losses, and gains of the U-slot antenna at different arm lengths are shown in Fig. 6. First, the lengths of both arms are $27.8 \mathrm{~mm}\left(0.21 \lambda_{\circ}\right)$ long, and the U-slot antenna is linearly polarized. $\mathrm{L}_{\mathrm{ur}}$ is then shortened. The two orthogonal modes can be observed from the smith chart and the return loss of the antenna when $\mathrm{L}_{\mathrm{ur}}$ is reduced to $24.3 \mathrm{~mm}(0.19 \lambda \mathrm{o})$. Further reduction of $\mathrm{L}_{\mathrm{ur}}$, better axial ratio can be achieved. The optimum value of $\mathrm{L}_{\mathrm{ur}}$ is $22.8 \mathrm{~mm}(0.18$

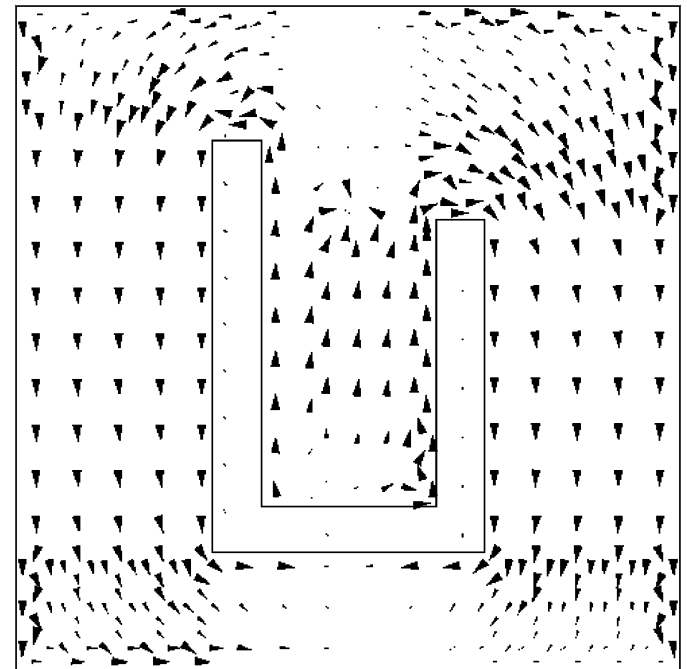

Fig. 7. Simulated surface current on the U-slot patch antenna.

$\lambda \mathrm{o}$ ) and the $3 \mathrm{~dB}$ axial ratio bandwidth is $4 \%$, ranged from 2.28 to 2.375 GHz. The best axial ratio is about 0.2 at $2.32 \mathrm{GHz}$. The ratio between the two arms for this best circular polarization is about 0.8 .

If we further reduce $\mathrm{L}_{\mathrm{ur}}$ to $0.0 \mathrm{~mm}$, i.e., the U-slot becomes a L-slot, the antenna will be still circularly polarized and has $3 \mathrm{~dB}$ axial ratio bandwidth of $4 \%$. However, the return loss of the antenna increases and the average gain decreases to $5 \mathrm{dBi}$. The antenna will not be suitable for most applications. Extra matching circuits will be required to improve the return loss.

In Fig. 6(a), it can also be observed that the frequency of minimum axial ratio shifts to higher frequency with shorter arm length $L_{u r}$. The best axial ratio of the circularly polarized antenna appears at the middle frequency of the two orthogonal modes. Fig. 7 shows the surface current magnitude graph; we can observe that a shorter arm will provide a shorter surface current path which generates a higher orthogonal mode. Therefore, if the lower orthogonal mode remains unchanged, then the operating frequency of the best axial ratio (middle frequency between the two modes) will shift higher.

\section{CONCLUSION}

Circularly polarized U-slot microstrip patch antennas have been presented. The U-slot can not only be used for increasing the impedance bandwidth, but also the axial ratio bandwidth. The asymmetrical structure of the U-slot provides two different current paths for the two orthogonal modes required for circular polarization. The measured impedance bandwidth $\left(\left|\mathrm{S}_{11}\right|<-10 \mathrm{~dB}\right)$ and the $3 \mathrm{~dB}$ axial ratio bandwidth of the antenna are about $9 \%$ and $4 \%$, respectively. Average gain of $8 \mathrm{dBi}$ has been achieved across the pass band. The $3 \mathrm{~dB}$ beamwidth of the antenna in both $x z$ - and $y z$-plane are about $58^{\circ}$. The $15 \mathrm{~dB}$ difference can be observed between LHCP and RHCP radiation.

\section{REFERENCES}

[1] T. Huynh and K. F. Lee, "Single-layer single-patch wideband microstrip antenna," Electron. Lett., vol. 31, no. 16, pp. 1310-1312, Aug. 3, 1995.

[2] K. F. Lee, K. M. Luk, K. F. Tong, Y. L. Yung, and T. Huynh, "Experimental study of the rectangular patch with a U-shaped slot," in Antennas and Propagation Society Int. Symp. AP-S Digest, Jul. 21-26, 1996, vol. 1, pp. 10-13.

[3] K. F. Tong, "Design of broadband microstrip antennas," Ph.D. dissertation, City University of Hong Kong, Kowloon, 1997.

[4] K. F. Lee, K. M. Luk, K. F. Tong, Y. L. Yung, and T. Huynh, "Experimental study of a two-element array of U-slot patches," Electron. Lett., vol. 32, no. 5, pp. 418-420, 1996. 
[5] K. F. Lee, K. M. Luk, K. F. Tong, Y. L. Yung, and T. Huynh, "Experimental and simulation studies of the coaxially-fed U-slot rectangular patch antenna," Proc. Inst. Elect. Eng. Microwaves, Antennas and Propagation, vol. 144, no. 5, Oct. 1997.

[6] K. F. Tong, K. M. Luk, K. F. Lee, and R. Q. Lee, “A broadband U-slot rectangular patch antenna on a microwave substrate," IEEE Trans. Antennas Propag., vol. 48, no. 6, p. 954, Jun. 2000.

[7] J. R. James, P. S. Hall, and C. Wood, Microstrip Antenna Theory and Design. London, U.K.: Peter Peregrinus, Ltd., 1981.

[8] I. J. Bahl and P. Bhartia, Microstrip Antennas. New York: Artech House, 1980.

\section{Probe Fed Stacked Patch Antenna for Wideband Applications}

\author{
M. A. Matin, B. S. Sharif, and C. C. Tsimenidis
}

\begin{abstract}
A new design of a U-slot microstrip antenna with an E shaped stacked patch is presented that achieves an impedance bandwidth of $59.7 \%$. Parameters such as substrate thickness, slot length, width are investigated and design results from parametric simulations are presented. The electric current distributions on the patch and the radiation patterns are also demonstrated in this paper.
\end{abstract}

Index Terms-E-shape patch, microstrip, U-slot antenna, wideband.

\section{INTRODUCTION}

Microstrip patch antennas are currently widely used particularly since they are lightweight, compact and cost effective; however, their main disadvantage is their narrow bandwidth. Therefore, various designs have been proposed in the literature to improve their bandwidth, including the use of thicker substrates, different shape patches and probes, addition of parasitic patches [1]-[4] and cutting of slots [5]-[7]. Examples of cutting slots include probe-fed U-slot patch antennas [5], double-C patch antennas [6], and E-shape patch [7] antennas which provide excellent bandwidths. The conventional U-slot patch antenna achieves an input impedance bandwidth of $30 \%$ and its impedance characteristics are further improved with electromagnetic coupling using an L-probe and stacked rectangular patch [3] which has a $44.4 \%$ bandwidth. When the two parallel slots in the U-slot patch are extended to the edge, an E-shape patch is obtained [6]-[8]. The E-shaped patch also provides wideband characteristics and the bandwidth is further increased to $44.9 \%$ by stacking a second patch above it in addition to using a washer on the probe [2]. More recent research on probe fed stacked patch for ultrawideband (UWB) applications has resulted in 54\% bandwidth [4]. In this paper, we propose a wideband patch antenna with simple coaxial feed configuration based on the conventional U-slot patch antenna stacking with an E-shaped patch that is capable of achieving an impedance bandwidth of $59.7 \%$. A SMA connector is used as a coaxial probe which is connected to the U-slot patch. The feed probe is located close to patch centre for good excitation of the proposed antenna over the wide bandwidth.

Manuscript received October 25, 2006.

The authors are with the School of Electrical, Electronic and Computer Engineering, University of Newcastle upon Tyne, Merz Court NE1 7RU, U.K. (e-mail: m.a.matin@ncl.ac.uk; bayan.sharif@ncl.ac.uk; charalampos. tsimenidis@ncl.ac.uk).

Digital Object Identifier 10.1109/TAP.2007.901924
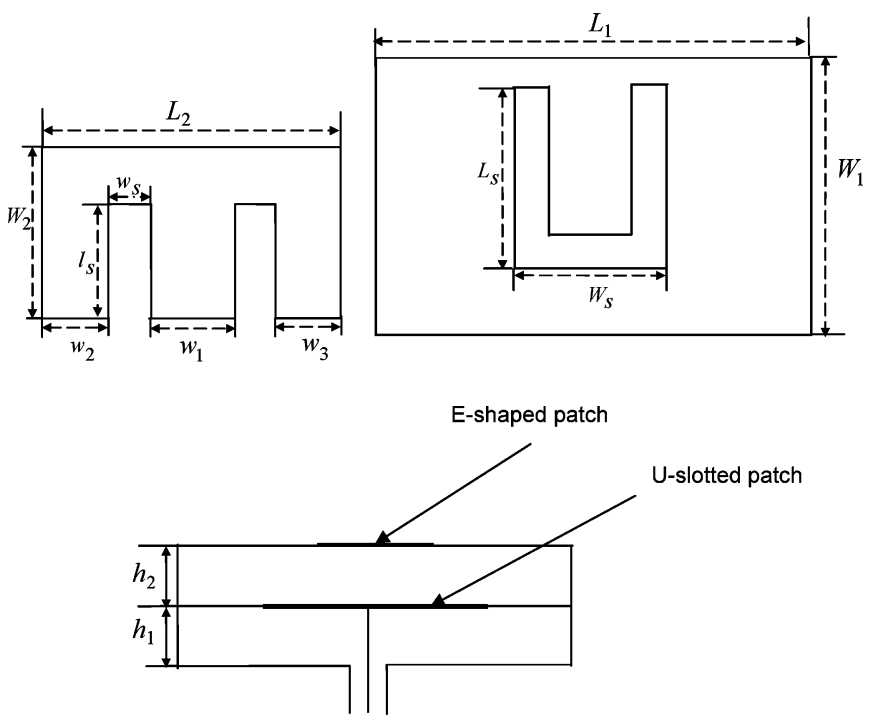

Fig. 1. Antenna structure.

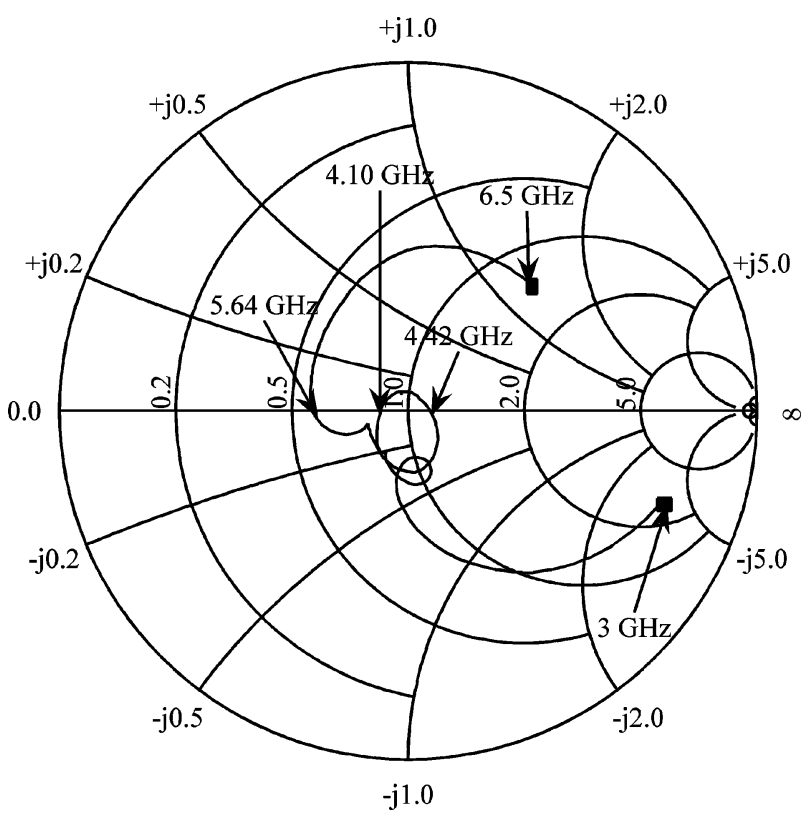

Fig. 2. The measured input impedance curves.

\section{ANTEnNa Design ANd PeRformance}

The configuration of the proposed antenna is shown in Fig. 1. This antenna consists of an E-shaped upper patch and a U-slot lower patch fed by a vertical probe which is an extension of the inner conductor of a coaxial feed line. The U-slot is placed on a dielectric substrate with dielectric constant of 1.1 and thickness of $6 \mathrm{~mm}$. To expand the antenna bandwidth, an E-shaped patch with another dielectric substrate is stacked on top of the lower U-slot patch. The geometrical shape of the upper patch resembles the letter "E" as two parallel slots are incorporated within it. The E-shaped patch is essentially formed by removing the lower portion of a U-slot that which has a low current distribution. Therefore, in the resulting antenna structure, more parameters can be varied than with a simple patch stacking. In this case careful optimization can be applied to control the coupling level between the patches to enhance the antenna bandwidth without splitting the operation band. A further increase in the bandwidth is also possible through incorporating a small washer to cancel the reactance of the probe at 